\title{
Nutritive content of lentil
}

\begin{abstract}
Lentil (Lens culinaris) is a very important nutritious crop, grown, consumed throughout the world due to its high macro and micronutrients contents, including all the minerals. The nutritive components of lentil have several beneficial influences on human health. The current review aims to highlight the present knowledge on the mineral, amino acid, lipids, vitamins and carbohydrate composition of lentils. Thereby, a literature search was conducted using reliable sources: Elsevier, Research gate, Springer, etc to understand the overall nutritive status of lentils.
\end{abstract}

The proximate composition of lentils is similar when compared with other legumes but the seed contains low concentrations of fat, fiber. Lentils supply a reasonably balanced range of all minerals. Lentils contain a number of anti-nutritive factors and these may be controlled either by processing or possibly by plant breeding programs. Anti-nutritive factors are less important In human diets because of cooking and processing which normally occur prior to eating, Lentils have a potential as a protein concentrate and could be processed to produce many products similar to those produced from soya beans.

Lentils should be used for a variety of purposes, mainly towards eliminating malnutrition, on the condition of being well-balanced. Lentils should be incorporated either in snacks or while preparing household, school, or hospital meals, particularly in developing countries.
Volume 12 Issue I - 2022

\author{
Harshita Sharma,' Naleeni Ramawat,' Charu \\ Gupta ${ }^{2}$ \\ 'Amity Institute of Organic Agriculture, Amity University Uttar \\ Pradesh, India \\ ${ }^{2}$ Amity Institute of Herbal Research \& Studies, Amity University \\ Uttar Pradesh, India
}

Correspondence: Charu Gupta Amity, Amity Institute Of Herbal Research \& Studies, Amity university Uttar Pradesh, Sec125, Noida-20 3 I 3, India, Tel 0|20-4392549,

Email cgupta@amity.edu

Received: January 24, 2022 | Published: February 18, 2022

Keywords: nutrients, lentil, composition, physiological functions, legumes

\section{Introduction}

The lentil (Lens culinaris or Lens esculenta) is an edible legume. It is a perennial plant with lens-shaped seeds. It is around $40 \mathrm{~cm}(16$ in) tall, and the seeds are produced in pods, each with two seeds. Canada and India produce the majority of the world's food crops, accounting for 58 percent of overall production. Lentil is a valuable food crop. It is a food with a high dietary benefit, generally replaces animal protein in the poor groups of the populace and is turning out to be progressively appealing as a significant part of vegetarian diets in developed countries.

Right now, the issue of food and feed protein insufficiency is turning out to be progressively important in the worldwide economy. An increment in grain legume yield production is one of the principle key undertakings of farming in tackling the arrangement of food security for the total populace. The protein issue ought to be settled basically utilizing grain vegetables. Lentil is quite possibly the most far reaching high-protein food grain legume crops. It is a significant maker of naturally important absorbable protein. Its substance in the grains of various assortments adds up to 22-36\% (Pavlovskaya et al., 2010; Kostikova et al., 2010). Lentil is a yield of flexible use: Food, feed and specialised. It contains nutrients "A", "PP", "E", "B1", "B2", "B5", "B6", "B9" (folic acid) and beta-carotene.

It contains amino acid tryptophan, which transforms into serotonin in the human body, the purported "nutrient of joy". Its grain waste and feed are a fantastic feed for domesticated animals. Lentil contains all fundamental amino acids (Thavarajah et al., 2011). Lentil doesn't aggregate destructive and harmful components, nitrates, or radio nuclides. Subsequently, lentil filled any place on the planet can be considered an eco-friendly product. The world's production of lentils was about 2.83 million metric tons, coming from Canada (36.9\%) and India (28.7\%), followed by Nepal, China and Turkey.

\section{Objective}

The main objectives of this paper are:

a. To have a better understanding of the nutritive aspects of lentil.

b. To study about lentil sowing, production and varieties.

c. To study about the research done so far on the following topic.

d. To have a better understanding of the composition of lentil and its uses (Figure 1).

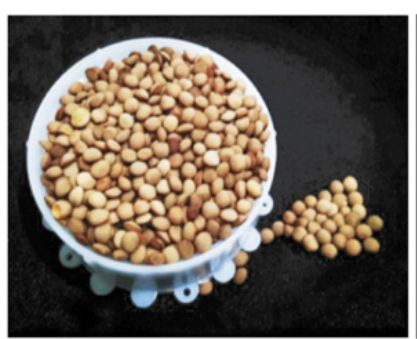

\begin{tabular}{|} 
Kingdom: Plantae \\
Subkingdom: Angiosperm \\
Division: Eudicots \\
Subclass: Rosids \\
Order: Fabales \\
Family: Fabaceae \\
Subfamily: Faboideae \\
Tribe: Vicieae \\
Genus: Lens \\
Species: culinaris
\end{tabular}

Figure I Nutritive aspects of lentil.

\section{Mineral composition of lentil seeds}

Lentil grain is a plentiful source of minerals. The mineral creation of lentil seeds has been researched and inspected by Wassimi et al, ${ }^{1}$ Summerfield et $\mathrm{al}^{2}$ cause to notice the way that previous rundowns of mineral composition ought to be treated with some reservation as the techniques for analysis and insightful accuracy have worked on drastically as of late. The concentration of minerals in the cooked entire seed and the kernel when contrasted and their raw counterparts is displayed in Table 1 underneath. This affirms the perception that cooking lentil kernels brings about a loss of every single mineral component or nutrient. 
Table I Mineral composition of lentil in raw and cooked seed (whole seed and kernel)

\begin{tabular}{|c|c|c|c|c|c|c|c|c|c|c|c|c|c|c|}
\hline & $\mathrm{Ca}$ & $\mathbf{K}$ & $\mathbf{P}$ & $\mathbf{M g}$ & $\mathbf{S}$ & $\mathbf{F e}$ & $\mathbf{Z n}$ & $\mathrm{Cu}$ & $M n$ & $\mathrm{Na}$ & I & B & $\mathrm{Se}$ & Mo \\
\hline g/kg & \multicolumn{14}{|c|}{ mg/kg } \\
\hline \multicolumn{15}{|l|}{ Raw } \\
\hline Whole Seed & $\begin{array}{l}0.20- \\
1.60\end{array}$ & $\begin{array}{l}5.4- \\
14.4\end{array}$ & $\begin{array}{l}0.72- \\
6.30\end{array}$ & $\begin{array}{l}0.70- \\
2.98\end{array}$ & $\begin{array}{l}1.2- \\
2.56\end{array}$ & $\begin{array}{l}54- \\
505\end{array}$ & $\begin{array}{l}18- \\
330\end{array}$ & $\begin{array}{l}2.0- \\
18.0\end{array}$ & $\begin{array}{l}8.4- \\
20.0\end{array}$ & $\begin{array}{l}13- \\
1100\end{array}$ & 0 & 1.5 & $\begin{array}{l}2.3- \\
6.0\end{array}$ & $\begin{array}{l}0.15- \\
1.60\end{array}$ \\
\hline Kernel & $\begin{array}{l}0.47- \\
0.88\end{array}$ & $\begin{array}{l}7.80- \\
80.62\end{array}$ & $\begin{array}{l}2.86- \\
5.22\end{array}$ & 0.91 & - & $\begin{array}{l}70- \\
101\end{array}$ & 31.5 & 8.9 & 14.2 & $\begin{array}{l}25- \\
840\end{array}$ & - & - & 0.56 & - \\
\hline \multicolumn{15}{|l|}{ Cooked } \\
\hline Whole Seed & $\begin{array}{l}0.16- \\
4.0\end{array}$ & $0.2-2.0$ & $\begin{array}{l}1.15- \\
4.68\end{array}$ & $\begin{array}{l}0.5- \\
0.90\end{array}$ & $\begin{array}{l}1.0- \\
1.2\end{array}$ & $22-24$ & $\begin{array}{l}29- \\
33\end{array}$ & $\begin{array}{l}8.0- \\
28.0\end{array}$ & $\begin{array}{l}\text { I7- } \\
\text { Aug }\end{array}$ & $\begin{array}{l}60- \\
200\end{array}$ & - & - & - & $\begin{array}{l}0.16- \\
1.82\end{array}$ \\
\hline Kernel & $\begin{array}{l}0.18- \\
0.84\end{array}$ & $\begin{array}{l}3.92- \\
8.11\end{array}$ & $\begin{array}{l}1.86- \\
3.17\end{array}$ & 0.3 & - & $\begin{array}{l}39.8- \\
370\end{array}$ & 11.8 & $\begin{array}{l}2.5- \\
9.0\end{array}$ & 0.5 & 21.1 & - & - & - & - \\
\hline
\end{tabular}

*Mineral content of lentils*

Three Mineral content of raw, dehulled, and cooked not set in stone in numerous past investigations that were done in various nations including USA (Pulse quality survey, 2018), Egypt (Annals of agricultural sciences), Pakistan (Haq et al., 2011), and Canada. ${ }^{3,4}$ By and large, the traditional preparation of lentil requires two stages: soaking (18 $\mathrm{h}$ to $24 \mathrm{~h}$ ) and cooking $\left(15 \mathrm{~min}\right.$ to $2 \mathrm{~h}$ at $\left.85-95^{\circ} \mathrm{C}\right)$.

Summerfield et al, ${ }^{2}$ proposed that the chemical composition of lentil seeds differed with the genotype and the soil composition where the lentil was grown. Wassimi et al, ${ }^{1}$ showed that distinctions in chemical composition influenced the time taken to cook the develop seeds.

Potassium was the most bountiful component going from 7.8 to $8.6 \mathrm{~g} / \mathrm{kg}$ in the kernel and 5.4 to 13.7 in the entire seed. More elevated levels of potassium $(24.2-29.0 \mathrm{~g} / \mathrm{kg})$ are reliably found in the entire seed. These qualities are in similar reach as other leguminous beans.

Lentils are richer in calcium than most cereals and apparently this component is found in the testa and kernel in roughly equivalent sums. Lentils contained practically the least degrees of calcium when contrasted and other usually eaten legume seeds. The $69 \%$ of the calcium in a diet contains $18 \%$ crude protein made up from lentils was held inside the test animal. Calcium retention tumbled to $49 \%$ in a comparable lentil diet with $12 \%$ rough protein.

Overall phosphorus is by all accounts amassed in the seed. The 40.5 to $42.9 \%$ of the complete phosphorus of entire lentils was contained in phytic acid. A somewhat higher sum, $43.7-44.0 \%$, of the all out phosphorus was contained in phytic acid in the kernel. The degree of phytic acid phosphorus in the testa and seed both fell barely on cooking.

The later investigations have shown that there is A critical relationship between's the cooking quality and $(\mathrm{Ca}+\mathrm{Mg})$ :P proportion in lentils. Significant degrees of phosphate in the seed lead to undeniable degrees of phytic acid synthesis. It is possible that low degrees of seed $\mathrm{Ca}$ and $\mathrm{Mg}$ and improved degrees of phytic acid might prompt great cooking quality in legumes. The negatively charged phytic acid effectively ties with charged cations, for example, $\mathrm{Ca}$ and $\mathrm{Mg}$ forming with pectin somewhat insoluble $\mathrm{Ca}$ and $\mathrm{Mg}$ pectates. The entire seed zinc levels show impressive variety yet apparently the zinc is concentrated in the seed.

The degree of sodium is of interest in light of its wide revealed range, from 13 to $849 \mathrm{mg} / \mathrm{kg}$ in entire seed and 25 to $840 \mathrm{mg} / \mathrm{kg}$ in the kernel. Some amount of sodium has been added in the industrial cooking processes. The given range for sodium in raw lentil kernel of 37 to $42 \mathrm{mg} / \mathrm{kg}$ and worth in cooked kernel of somewhere in the range of 19.1 and $22.1 \mathrm{~g} / \mathrm{kg}$.

Iron seems to be concentrated in the tests of lentils although a considerable range of values have been reported. The cooked seed and kernel contain by and large lower levels of iron. Iron-deficiency anemia is a difficult issue in numerous regions where lentils are consumed.

Dietary surveys would propose that albeit the iron admission has all the earmarks of being sufficient its bioavailability is low. In human studies the ingestion of iron from lentils went from 0.20 to 2.86 , mean $1.20 \%$. Comparable low degrees of iron absorption were additionally noticed for soya beans, mung beans and split peas.

\section{Physiological functions of lentil minerals}

Few physiological roles of lentil minerals in the body are given below:

\section{Iron \& copper}

Iron (Fe) is essential for practically all living creatures; it is engaged with a wide assortment of metabolic cycles, DNA synthesis, and electron transport. Copper $(\mathrm{Cu})$ is an important catalyst for haeme synthesis and it is in its many structure the third most common mineral in the body.

\section{Calcium and potassium}

Calcium $(\mathrm{Ca})$ is a significant supplement that is fundamental for a few functions in human being; it is $100 \%$ found in bone and teeth. Ca metabolism includes different nutrients like protein, vitamin D. Potassium $(\mathrm{K})$ is a fundamental nutrient; it plays a significant part in keeping up with cell work.

\section{Magnesium}

Magnesium $(\mathrm{Mg})$ is required as a cofactor for more than 300 enzymatic responses; $\mathrm{Mg}$ is important for muscle contraction (counting that of the heart), blood pressure, etc and is required for the amalgamation of DNA, RNA, and proteins.

\section{Phosphorus}

Phosphorus $(\mathrm{P})$ is required for vital biological reactions that maintain the normal homoeostatic control of the cell and is a fundamental segment of cell structures, including nucleic acids and cell membranes. 


\section{Sodium}

Sodium $(\mathrm{Na})$ is important for human health to maintain volume of plasma, regulating body water content, transmission of nerve impulses, and normal cell function; however, its excess in human diet leads to high blood pressure.

\section{Antinutritonal factors (mineral chelating agents)}

Despite the fact that lentils are plentiful in minerals, their bioavailability is restricted because of the presence of different antinutritive variables, for example, phytates, phenolic compounds, and oxalic acid. This can prompt numerous medical conditions, among which is iron deficiency.

All significant sorts of food polyphenols are emphatically ready to hinder dietary non-haem Fe retention. Oxalates in food unequivocally chelate with dietary minerals, for example, calcium precipitates as insoluble salts accumulating that lead to the development of renal problems, such as kidney stone formation.

Phytic acid that addresses $1 \%$ to $5 \%$ by weight of most pulses, phytic acid represses the ingestion of $\mathrm{Fe}, \mathrm{Zn}, \mathrm{Ca}$, and $\mathrm{Mn}$, yet not $\mathrm{Cu}$. Phytic acid marginally impacts $\mathrm{Ca}$ and $\mathrm{Mg}$ retention. Truth be told, $\mathrm{Fe}$ and $\mathrm{Zn}$ inadequacies are normal in babies and small kids, particularly in non-industrial nations; subsequently, their bioavailability from correlative food is a significant concern. Various strategies have been created to diminish the phytic acid substance in food and work on its nourishing quality, which becomes poor due to such anti-nutrients factors.

The method for preparing, like cooking, brings about significant decrease in tannins and phytic acid in pulses. ${ }^{5}$ Moreover, food preparation techniques and other dish parts additionally impact the phytic acid fixation and other anti-nutritional factors.

\section{Proximate composition}

An enormous number of authors have distributed fractional examinations of the composition of lentil seed. These have been summed up in the past by Tannous et al 1978 and the F.A.O.

On an entire seed premise their crude protein content is equivalent with faba bean and is higher than in chickpeas yet lower than soya beans or lupins. Removal of the testa has little impact on in general crude protein content. Cooked lentils have an insignificantly lower crude protein content than raw seeds.

Seed protein content changes significantly among varieties and plant breeders could use this data to deliver cultivars with a high protein concentration. There is a wide scope of changeability in seed protein content and this is helpful for plant breeders keen on giving cultivars yielding high protein. The protein content of lentils filled in generally varying areas in India showed that there were significant differences in the crude protein content of lentils grown in different locations but differences in crude protein content due to variety were not significant.

In the Williams et al 1975 survey it was noticed that the little seeded types contained the most elevated protein levels of a wide scope of lentil races developed under standard conditions in a glasshouse they noticed a bimodal dispersion of protein content with tops in the district of 18-19 and $22-23 \%$ crude protein. Lentils imported from India showed the least variety.

The measure of oil (ether extract) present in the seed of lentils is low and never transcends $4 \%$. The crude fiber content of entire lentils is typically low and ranges from 1.4 to $5.9 \%$. The vast majority of this fiber is found in the testa. Dehusking of lentils to reduce the fiber content is likely also to increase the protein. The ash content of raw lentils goes from 1.9 to $5.7 \%$. Somewhat more elevated levels of ash are found in the testa.

\section{Lipid composition}

Lipid concentration of lentils is low and ranges from 0.6 to $3.9 \%$ of the entire seed (Table 2). Marginally higher lipid concentrations are available in the kernel than in the testa. The composition of the unsaturated fats found in lentils is given in Table 3 beneath.

Table 2 Proximate composition of raw and cooked lentil (whole seed and kernel)

\begin{tabular}{llllll}
\hline & $\begin{array}{l}\text { Crude } \\
\text { protein }\end{array}$ & $\begin{array}{l}\text { Ether } \\
\text { extract }\end{array}$ & $\begin{array}{l}\text { Crude } \\
\text { fibre }\end{array}$ & $\begin{array}{l}\text { Nitrogen } \\
\text { free } \\
\text { extract }\end{array}$ & Ash \\
\hline Raw & & & & & \\
Whole Seed & $19.5-35.5$ & $0.6-3.9$ & $1.4-5.9$ & $52.5-69.7$ & $1.9-5.7$ \\
Kernel & $19.5-32.5$ & $0.9-2.8$ & $0.2-3.0$ & $65.3-68.3$ & $2.2-3.0$ \\
Cooked & & & & & \\
Whole Seed & $20.5-31.4$ & $0.7-1.6$ & $2.7-4.9$ & $61.4-69.4$ & $1.4-3.5$ \\
Kernel & $22.5-29.0$ & $0.6-2.2$ & $0.5-3.9$ & $60.4-66.4$ & $1.0-2.8$ \\
\hline
\end{tabular}

Proximate composition of lentils (\% of DM)

*All values converted to an oven dry basis*

Table 3 Lipid composition in saturated and unsaturated form of whole seed and kernel

\begin{tabular}{lll}
\hline & Whole seed & Kernel \\
\hline Saturated & & \\
14 & $0.3-0.9$ & - \\
16 & $12.3-19.7$ & 18 \\
18 & $0.9-3.7$ & $\mathrm{~T}$ \\
20 & $0.3-2.1$ & - \\
22 & 0.5 & - \\
24 & 0.2 & - \\
Unsaturated & & \\
16.1 & $0.2-0.4$ & - \\
18.1 & $16.2-30.0$ & 17 \\
18.2 & $17.5-50.6$ & 54 \\
18.3 & $8.6-16.0$ & 10 \\
20.1 & $0.5-1.5$ & 1 \\
Unsaturated/saturated & $2.5-4.9$ & 4.4 \\
& T trace (less than $0.5 \%)$ \\
\hline
\end{tabular}

Fatty acid composition of raw lentils (as a percentage of total fatty acids)

The high proportion of polyunsaturated fatty acids is imperative especially as the greater part of this division is comprised of linoleic acid. Linoleic acid (18:3) which oxidizes rapidly and produces 'off flavor's is present in amounts ranging from 8.6 to $16.0 \%$ total fatty acids. This is higher than the sums found in soya bean $(7.3 \%)$ however similar to the level in cowpea (17\%). 
Unsaponifiable matter comprised of $3.7 \%$ of the all out fat substance of lentils. This division contained somewhere in the range of 72 and $80 \%$, beta-sitosterol and $11-14 \%$ campesterol and $6-10 \%$ stigmasterol, 4alpha-Methyl sterols were seen to be minor constituents of unsaponifiable part and their separation proved to be different.

\section{Vitamin composition}

The vitamin composition of raw and cooked lentils is displayed in Table 4. The testa appears to contain significant degrees of thiamin, riboflavin and niacin and surprisingly the stripped lentil seeds can be viewed as a rich source of these vitamins when compared with the levels found in cereals. Extensive losses of thiamin and riboflavin appear to happen on cooking.

Table 4 Vitamin composition of raw and cooked seed (whole seed and kernel)

\begin{tabular}{|c|c|c|c|c|}
\hline & Raw & & Cooked & \\
\hline & $\begin{array}{l}\text { Whole } \\
\text { seed }\end{array}$ & Kernel & $\begin{array}{l}\text { Whole } \\
\text { seed }\end{array}$ & Kernel \\
\hline Thiamine & $2.4-7.2$ & $2.8-4.6$ & 1.3 & $0.6-1.7$ \\
\hline Riboflavin & $2.0-4.9$ & I.I-3.0 & - & $0.2-0.3$ \\
\hline Niacin & $20.2-32.0$ & $2.0-9$ & - & - \\
\hline Retinol & 112 & - & - & - \\
\hline$\beta$-Carotene & 200 & - & - & - \\
\hline Biotin & 0.132 & - & - & - \\
\hline Folic acid & 15 & - & - & - \\
\hline Pantothenic acid & $15-16$ & - & - & - \\
\hline Pyridoxine & 5 & - & - & - \\
\hline$\alpha$-Tocopherol & 20 & - & - & - \\
\hline Ascorbic acid & $3-33.7$ & 4 & - & - \\
\hline Choline & I.I & - & - & - \\
\hline Inositol & 1300 & - & - & - \\
\hline Vitamin K & 2.5 & - & - & - \\
\hline
\end{tabular}

*Vitamin composition of lentil $\mathrm{mg} / \mathrm{kg}^{*}$

Lentils in the same manner as most types of legumes contain just limited quantities of carotene and retinol. The significant scope of ascorbic acid substance recommend that a few examples might have been put away for quite a while before examination. Delayed cooking needed for the planning of lentils would absolutely destroy the remaining ascorbic acid.

Germination of lentil seeds increased the ascorbic acid substance from 9.0 to $77.5 \mathrm{mg} / \mathrm{kg}$ in 4 days. Simultaneously the riboflavin content expanded uniquely from 3.2 to $3.9 \mathrm{mg} / \mathrm{kg}$. Lentils are somewhat acceptable sources of folic acid and alpha-tocopherol and they contain unassuming degrees of pantothenic acid when contrasted and different food sources.

\section{Carbohydrate composition}

Carbohydrate concentration in entire lentils goes from 53 to $70 \%$ while the kernel contains 65 to $68 \%$. Somewhat lower levels of carbohydrates are seen in the cooked kernel, 60-66\%, recommending a few misfortunes happen in the cooking water. The accessible carbohydrate portion incorporates free sugars, oligosaccharides and starches and ranges from 426 to $625 \mathrm{~g} / \mathrm{kg}$. The inaccessible carbohydrate division (e.g., acid-detergent fiber) goes from 50 to 56 $\mathrm{g} / \mathrm{kg}$ in the entire seed tumbling to $20 \mathrm{~g} / \mathrm{kg}$ in the kernel alone.

Lentils, in a similar manner as peas and beans, contain moderately low concentrations of free sugars. Singular free sugars have been chiefly recognized by Sosulski et al. ${ }^{5}$ while sucrose has been determined in whole seed by Schweizer et al. ${ }^{6}$

The starch content went from 347 to $631 \mathrm{~g} / \mathrm{kg}$ in entire raw seed. More significant levels were found in the kernel, 525 to $634 \mathrm{~g} / \mathrm{kg}$, recommending that significant extents of the insoluble carbohydrates are found in the testa.

The non-starchy polysaccharides extricated by trichloroacetic acid addressed $0.8 \%$ of entire dry lentil seeds. Arabinose was the significant constituent of this division. The cell wall material separated from lentil kernels contained $73 \%$ pectic polysaccharides related with $12 \%$ cellulose and again arabinose was the major pectic sugar of this portion. The testa establishes a little part of the entire seed (4.5\%) and that this portion contained $1.7 \%$ lignin, $33 \%$ cellulose and $53 \%$ nonstarchy polysaccharides.

Alpha-Galactosides are known to establish the significant part of the carbohydrates in legume seeds; significant proportions of raffinose, stachyose and verbascose have been identified. These oligosaccharides are generally found in the kernel of lentils; lower levels are found in entire cooked seed recommending a few losses during cooking.

Raffinose, stachyose and verbascose concentrations are significant in light of the fact that the human digestive tract doesn't produce a-1,6-galactosidase (EC3.2.1.22) enzymes capable of degrading these compounds, So they are available to be broken down by the microbial flora in the large intestine.

\section{Amino acid composition}

The amino acid compositions of lentils given in Table 5 beneath are contrasted and the ideal protein proposed by FAO (1973). In addition the amino acid composition of egg albumen has been included as it is used as a reference standard in animal feeding experiments and is known to give the highest biological value of any natural protein product.

The comparison shows that lentils might be inadequate in some amino acids. The restricting fundamental amino acids in lentils are methionine and cystine. Lentils are poor sources of tryptophan. The significant reaches in methionine and cystine substance propose that it could be feasible to choose for higher sulfur amino acid substance. Lysine, arginine and histidine additionally showed a considerable variation between samples.

The values for amino acid content of raw and cooked lentil seeds displayed in Table 5 beneath are results gotten distinctly from standard column chromatographic methods. The analysis of the sulfur amino acids and tryptophan present special problems due to their differential destruction during hydrolysis. Therefore the values In Table 5 show not only biological variation but variation in experimental methodology as well.

The tryptophan content of lentil protein was reliably higher than other Indian developed lentils. The lysine content of both raw and cooked lentils is by all accounts well over the suggested levels. What's more the accessibility of lysine in entire seed is high, going from 91 to $97 \%$. The addition of lentils to diets based on cereals, starchy roots or tubers which are known to be deficient in lysine provides a balanced overall intake of lysine. 
Table 5 Carbohydrate composition of raw and cooked lentil in soluble sugars and oligosaccharides and insoluble carbohydrates

\begin{tabular}{|c|c|c|c|c|c|c|}
\hline & \multicolumn{2}{|c|}{ Whole Lentils } & \multicolumn{2}{|l|}{ kernel } & $\begin{array}{l}\text { FAO"Ideal } \\
\text { protein" }\end{array}$ & Whole egg protein \\
\hline Threonine & $3.00-4.60$ & $3.32-4.90$ & $3.57-4.4$ & $3.38-4.8$ & 4 & $3.7-4.9$ \\
\hline valine & $2.56-5.90$ & $4.13-5.57$ & $4.5-49$ & $4.42-4.7$ & 5 & $6.8-7.3$ \\
\hline Cystine & $0.3|-| .87$ & $0.32-2.14$ & I.06-I.I & $0.60-1.06$ & 3.5 & I.I-2.4 \\
\hline Isoleucine & $3.4-5.40$ & $3.55-4.08$ & $4.0-5.0$ & $4.00-4.2$ & 4 & $5.7-8.0$ \\
\hline Leucine & $6.1-8.62$ & $6.20-7.41$ & $6.7-7.4$ & $6.7-6.8$ & 7 & 9.2 \\
\hline Lysine & $5.75-9.60$ & $6.45-9.39$ & $6.03-7.78$ & $7.00-7.79$ & 5.5 & 7.1-7.2 \\
\hline Histidine & I.7-4.06 & $1.90-3.14$ & $2.18-3.36$ & $2.10-2.53$ & & $2.1-2.7$ \\
\hline Arginine & 6.4-99 & $5.98-7.93$ & $4.80-9.00$ & $7.57-7.70$ & & 5.8 \\
\hline Tryptophan & $0.5-11$ & $0.80-1.20$ & $0.72-1.00$ & $0.99-1.109$ & I & 1.5 \\
\hline \multicolumn{7}{|c|}{ Non-essential amino acids } \\
\hline Proline & $3.37-6.0$ & $3.10-5.95$ & $3.52-4.60$ & - & - & 6.7 \\
\hline Aspartic acid & $9.6-12.34$ & $10.24-12.30$ & $9.29-5.22$ & 11.26 & - & 8.3 \\
\hline
\end{tabular}

The cooking of whole lentils and lentil kernels brings about slight losses of every amino acid, aside from tryptophan and lysine which showed slight increases. They additionally saw that the general amino acid substance of the kernel was higher than the entire seed because of the low substance of protein in the testa, All other fundamental amino acids gave more than the sum suggested by FAO (1973).

Two exceptional amino acids, alpha-hydroxyarginine and alphahydroxyornithine, have been identified in lentil seed by Sulser and Stute (1974).$^{7}$ While losses appear to be small during soaking and pre-cooking of the seed, over $50 \%$ was lost on final cooking.

\section{Protein fractions in lentil}

The storage protein fraction comprises of the globulins which are the major proteins of legume seeds. The albumin proteins are a minor fraction and are mostly enzymic or non-storage proteins. Bhatty ${ }^{8}$ showed that the albumin fraction from lentils, though a minor proportion of the total seed protein content $(8.1 \%$ of total crude protein), contained a superior equilibrium of fundamental amino acids when contrasted and the globulin fraction. Specifically, the degrees of methionine, tryptophan, lysine and threonine were considerably higher in the albumin part. Globulins made up $34.3 \%$ of the crude protein content of lentils.

A trademark highlight of the amino acid substance of the globulin fraction was the exceptionally low methionine content $(0.6 \mathrm{~g} / 16 \mathrm{~g}$ $\mathrm{N})$. A significant improvement in the protein nature of lentils would happen if new assortments containing more elevated levels of the albumin fraction could be identified. This improvement is subject to the accessibility of genetic variability within cultivated lentil species and within wild species of lentil which are crossable with cultivated lentils. Bhatty ${ }^{8}$ has shown that for three wild lentil species $(L$. orientalis, L. ervoides and L. nigricans) the egg whites division went from 12.7 to $16.8 \%$ and the globulin went from 34.7 to $49.0 \%$ of the total lentil nitrogen.

The yields of the albumin and globulin protein fractions from the three wild species were more noteworthy than for developed lentils. ${ }^{9}$ Be that as it may, the complete amino acid substance of the three wild types of lentil were practically indistinguishable from one another and like the scope of qualities detailed in Table 5 for cultivated varieties of lentil.

Since lentils contain somewhere in the range of 19.5 and $35.5 \%$ protein they are utilized as a rich source of dietary protein in many agricultural nations, Protein healthful quality is subject to the amount and accessibility of the fundamental amino acids and lentils are by and large restricting in the sulfur-containing amino acids. The amino acid composition and, apparently, the protein quality might be modified by varietal contrasts and perhaps by developing area.

The small differences in protein quality that result from breeding programmes, agronomic practices or variations in processing are not easily measured. In addition the low digestibility of many legume proteins as well as the presence of some anti-nutritive factors must be taken into account when nutritional quality is being assessed. 
The protein efficiency ratio of lentil utilized was 0.73 contrasted and faba bean (1.09) and pea supper (1.45). The net protein proportion of lentil supper was again low (0.21) contrasted and pea 1.04 and faba bean 0.57 . The digestibility of protein in the lentil meal was likewise low (77.8) contrasted and pea (89,3 and 83.5). The lentils are a poor source of protein contrasted and Bengal gram (Cicer arietinum) and mung beans (Phaseolus aureus) however the quality can be particularly enhanced expansion of $0.1 \%$ methionine to the eating regimen. A five-day nitrogen balance experiment in man additionally showed that methionine was the first restricting amino acid in quite a while for man. ${ }^{10-17}$

\section{Conclusion}

A crucial challenge today is to make our food habits healthier and more sustainable. Hence, using pulse-based products, including lentils, is tremendously suggested over the world. The wholesome significance of lentils is certain because of the huge presence of minerals, polyphenols, and other required parts, whose utilization assumes a huge part in human health.

Protein is an essential segment of human diet and animal feed. Protein-poor diets can compromise normal bodily functions and have adverse consequences on health. End of dietary and feed protein deficiencies is an essential target for keeping up with human health and productivity of livestock.

Lentil (Lens culinaris) belongs to a group of high-protein food crops and lentil grains that are frequently used for cooking due to their ease of preparation and good digestibility. Lentils are profoundly nutritious and have a higher protein content than wheat, peas and kidney beans. In fact, lentils have the most noteworthy dietary benefits contrasted with all legumes. A $100 \mathrm{~g}$ segment of lentils has 310 calories and comprises of $24-35 \%$ protein, $48-53 \%$ carbohydrate, $0.6-2 \%$ fat and $2.3-4.4 \%$ minerals. The majority of the protein content $(80 \%)$ in lentils is found in the water-solvent division. Additionally, lentils have a high substance of fundamental amino acids and are a decent source of bioactive fundamental minerals, including the significant supplements $(\mathrm{K}, \mathrm{P}, \mathrm{Ca}, \mathrm{Mg}, \mathrm{Na})$ and minor components ( $\mathrm{Fe}, \mathrm{Zn}, \mathrm{Cu}$, $\mathrm{Mn})$, Lentils don't aggregate nitrates, poisonous components or radio nuclides to a huge degree and consequently can be considered as an environmentally unadulterated item. Rather than numerous different food varieties, lentils loose few nutrients following heating during cooking. Therefore more emphasis should be given on incorporating lentils in diet because of its high nutritive values.

\section{Acknowledgments}

None.

\section{Conflicts of interest}

The author states there are no conflicts of interest.

\section{Funding}

None.

\section{References}

1. Wassimi N, Abu-Shakra S, Tannous R, et al. Effect of mineral nutrition on cooking quality of lentils. Canadian Journal of Plant Science. 1978;58(1):165-168.

2. Summerfield RJ, Muehlbauer FJ. Mineral nutrient composition of lentil seeds. Communications in Soil Science and Plant Analysis. 1982;13(4):317-333.

3. Wang N, Hatcher D, Toews R, et al. Influence of cooking and dehulling on nutritional composition of several varieties of lentils (lens culinaris). LWT - Food Science and Technology. 2009;42(4):842-848.

4. Wang N, Daun J. Effects of variety and crude protein content on nutrients and anti-nutrients in lentils. Food Chemistry. 2006;95(3):493-502.

5. Sosulski F., elkowicz L, Reichert R. Oligosaccharides in eleven legumes and their air-classified protein and starch fractions. Journal of Food Science. 1982;47(2):498-502.

6. Schweizer TF, Horman I, Würsch P. Low molecular weight carbohydrates from leguminous seeds; a new disaccharide: Galactopinitol. Journal of the Science of Food and Agriculture. 1978;29(2):148-154

7. Gupta RK, Gangoliya SS, Singh NK. Reduction of phytic acid and enhancement of bioavailable micronutrients in food grains. Journal of Food Science and Technology. 2013;52(2):676-684.

8. Sulser H, F Sager. Identification of uncommon amino acids in the lentil seed (Lens Culinaris Med.). Experientia.1976;15;32(4):422-423.

9. Bhatty RS. Protein subunits and amino acid composition of Wild lentil. Phytochemistry. 1986;25(3):641-644.

10. Benayad A, Aboussaleh Y. Mineral composition of lentils: Physiological functions, antinutritional effects, and bioavailability enhancement. Journal of food quality. 2021.

11. Hefnawy T. Effect of processing methods on nutritional composition and anti-nutritional factors in Lentils (lens culinaris). Annals of Agricultural Sciences. 2011;56(2):57-61.

12. Hendek Ertop M, Bektaş M. Enhancement of bioavailable micronutrients and reduction of antinutrients in foods with some processes. Food and Health. 2018;159-165.

13. Jermyn W A. Production practices and economic importance of pea, lentil, faba bean and Chick pea in New Zealand and Australia. World Crops: Cool Season Food Legumes. 1988;1125-1133.

14. Meiners CR, Derise, NL, Lau HC, et al. The content of nine mineral elements in raw and cooked mature dry legumes. Journal of Agricultural and Food Chemistry. 1976;24(6):1126-1130.

15. Williams PC, Bhatty RS, Deshpande SS, et al. Improving nutritional quality of cool season food legumes. Expanding the Production and Use of Cool Season Food Legumes. 1994;113-129.

16. David McNeil, Philip C. Stevenson, et al. Lentil: An ancient crop for modern times. 2007th ed. Springer; 2007.

17. Geoffrey Peter Savage. The composition and nutritive value of lentils. 1st ed. New Zealand; 1988. 